\title{
How People with Multimorbidity and Psychosocial Difficulties Experience Support by Rehabilitation Coordinators During Sickness Absence
}

\author{
Veronica Svärd (iD) ${ }^{1-3}$ \\ Emilie Friberg (iD) \\ Azadé Azad iD 1,4 \\ 'Division of Insurance Medicine, \\ Department of Clinical Neuroscience, \\ Karolinska Institutet, Stockholm, SE-I7I \\ 77, Sweden; ${ }^{2}$ Department of Social Work \\ in Health, Karolinska University Hospital, \\ Stockholm, SE-I7I 76, Sweden; \\ ${ }^{3}$ Department of Social Work, Södertörn \\ University, Huddinge, SE-I4I 89, Sweden; \\ ${ }^{4}$ Department of Psychology, Stockholm \\ University, Stockholm, SE-II4 I9, \\ Sweden
}

Purpose: People with multimorbidity face a range of barriers in healthcare, and there is little knowledge about their challenges with regard to return-to-work (RTW). Rehabilitation coordinators, a new function in Swedish healthcare, support people in the RTW process. The present study had two aims: to explore what problems and barriers people with multimorbidity experience during their rehabilitation and RTW process and to explore in which domains the coordinators' support is perceived to be of importance.

Methods: Interviews were conducted with 12 persons with multimorbidity who had contact with a rehabilitation coordinator during their sickness absence. Thematic analysis was guided by the case-management ecological model; this analysis was revised and adapted to the Swedish context. Results: The participants experienced problems in all domains of the model, namely: "the healthcare system", "the labor market and the workplace system", "the sickness insurance system", and "the personal system". Rehabilitation programs that did not accommodate combinations of diseases, social complexities and needs were felt to lead to worse symptoms, thus hindering rather than promoting RTW. An overall finding regarding support by coordinators is that interventions, regardless of domain, were felt to be valuable for people with multimorbidity. The coordinator was perceived to give most support by providing advice about and coordination with healthcare and employers. Sometimes the coordinator gave advice and coordination regarding the Social Insurance Agency, very occasionally the Public Employment Services. The coordinator gave least advice and coordination about social difficulties that hindered rehabilitation and RTW processes.

Conclusion: People with multimorbidity perceive rehabilitation coordinator interventions as important in all domains investigated. Lack of advice and coordination, or rehabilitation programs that were not modified to the complexities of individual's circumstances, were associated with prolonged sickness absence, worse health, or social risk factors not being recognized.

Keywords: sickness absence, multimorbidity, psychosocial difficulties, social complexity, rehabilitation, return-to-work, coordination

\section{Introduction}

The treatment and rehabilitation of people with multimorbidity often involves challenges and obstacles, ${ }^{1}$ and multimorbidity seems to interfere with rehabilitation and return to work (RTW) after sickness absence (SA). ${ }^{2}$ Multimorbidity, defined as the coexistence of a chronic disease and at least one other disease, functional limitation or biopsychosocial barrier (including psychosocial difficulties), ${ }^{3}$ increases with age, but
Correspondence: Veronica Svärd

Division of Insurance Medicine,

Department of Clinical Neuroscience,

Karolinska Institutet, Stockholm, SE-I7I

77, Sweden

Email veronica.svard@ki.se 
the relative majority of persons with multimorbidity are of working age. ${ }^{4}$ Research on multimorbidity from a patient perspective has been called for, ${ }^{5,6}$ centering on those of working age, as the scientific literature has generally focused on older people. ${ }^{7}$ Multimorbidity ${ }^{8-10}$ and psychosocial factors such as job strain, anxiety, depression, older age and low education ${ }^{11}$ are all considered as barriers to RTW, and should therefore be taken into consideration in the RTW process. ${ }^{12}$ The SA can be long and the RTW process complex, especially for those with diffuse or numerous problems which do not neatly fit into the remit of different authorities, welfare organizations, and a healthcare system siloed according to single diseases. ${ }^{1,12,13}$ Living with multimorbidity often involves psychosocial difficulties that are correlated with increased risk of SA. These include low education, unemployment, long-term effects of adverse psychosocial conditions in childhood, and work-family conflicts. ${ }^{12,14}$ Other difficulties, especially in women, include informal caregiving for older relatives, ${ }^{15}$ children ${ }^{16,17}$ or other family members with chronic diseases. ${ }^{18}$ Further, the complex situation some people with multimorbidity live with involves challenges in dealing with an array of contacts. For a successful RTW process, RTW coordination is recommended to improve the quality of the interaction between people on SA (regardless of disease) and the healthcare providers, authorities, and other contacts. ${ }^{19}$

Studies focusing explicitly on RTW interventions in people with multimorbidity are rare, but recent systematic reviews have found that workplace-oriented and multidisciplinary interventions and programs are the most supportive for RTW among people with chronic diseases, ${ }^{20,21}$ who often also live with multimorbidity. There is a lack of research into the importance of RTW coordinators for people with multimorbidity although it has been hypothesized that they are especially important for this group. ${ }^{22}$ The literature reviews of RTW interventions have in general found no or only a weak effect of RTW programs which include coordinator support, ${ }^{23,24}$ whereas others stress the importance of cooperation during the RTW process. ${ }^{25-27}$

\section{Rehabilitation Coordinators}

Rehabilitation coordinators (RECO) have been introduced in Swedish healthcare over the last 10-15 years. Their purpose is to facilitate RTW for people on SA. Since February 2020, healthcare services are obliged to offer patients on SA rehabilitation coordination if needed. These RECOs should support the patient in the rehabilitation process. They should initiate and promote coordination with healthcare services (for example, physicians, psychologists, health social workers) and other stakeholders (for example, the employer, Social Insurance Agency (SIA), and the social services). They should also provide other support which helps the RTW process. RECO should also pay attention to risk factors in work, home and social life which might prolong SA, identify patients who need coordinating support, and promote equality in the RTW process. ${ }^{28}$ Most often, the RECO is a registered physiotherapist, occupational therapist, nurse, or a health social worker.

The effects of implementing RECO in healthcare are however still unclear, and research into the patient experience of support from a coordinator in the RTW process is also scarce. To the best of our knowledge, no study of RTW coordination from the perspective of individuals with multimorbidity has been carried out previously, even though these individuals are more likely to have difficulty coordinating contacts and communicating a complex situation, and to encounter difficulties in the rehabilitation process.

A few interview studies have looked at how people on SA experience support provided by RECO. They show that people with common mental disorders or spinal cord injury have found that RECOs provide stability in the RTW process, by for example, enhancing communication and collaboration and bridging the gaps between the person on SA, the employer and other stakeholders. ${ }^{29-32}$ RECO have also been found to balance relationships, transfer knowledge, ${ }^{30,32}$ and change attitudes about fatigue syndrome among employers and colleagues at the workplace. ${ }^{30}$ The RECO have also been described as the main professional persons on SA were in contact with during their rehabilitation, and that they provided daily structure, practical and mental support, as well as encouragement. $^{32}$ However, to promote successful RTW coordination for the broad range of people on SA there is a need for more research, including into the experience of people with several diseases and problems.

\section{The Case-Management Ecological Model}

In an overview of systematic reviews, Bültmann and Brouwer point to how the scientific knowledge of work disability and RTW promotion has evolved during recent decades, from a biomedical focus on rehabilitation to a biopsychosocial perspective recognizing psychosocial factors' significant effect on work ability and RTW rates. ${ }^{33}$ Even though symptoms and diseases originate from a health condition, the authors found that the transition to chronic disability often depends on psychosocial factors, 
which therefore must be taken into consideration when aiming to prevent long-term SA. Bültmann and Brouwer further address the lack of research on multimorbidity in relation to work disability and psychosocial factors. ${ }^{33}$

Work ability has been described as the balance between the individual's work and their resources (health, competence, values), a balance that is influenced by the workplace, family and close community. Actions from both the worker, the employer, the immediate social environment and relevant organizations can be effective in promoting these resources and thus the individual's work ability. ${ }^{34}$ In an overview of conceptual work disability models, CostaBlack, Feuerstein and Loisel also argue for the need to understand how organizational and structural conditions impact work disability. ${ }^{35}$ They propose the casemanagement ecological model, as it has a holistic approach which pays attention to various social structures and a broader arena of social actors. This model was initially constructed to guide case management of work disability due to musculoskeletal disorders, but has been applied to various other medical conditions to prevent prolonged work disability. The model uses a biopsychosocial perspective that considers how multi-influencing systems may impact work disability, and promote a multi-problem-solving approach by identifying actors and factors on various levels in four domains around the worker:

- the personal system and coping,

- the healthcare system,

- the work place system, and

- the legislative and insurance system. ${ }^{35}$

This model has the potential to identify how both work and non work-related problems affect rehabilitation, and may help to tailor the strategies for RTW. Costa-Black and colleagues also suggest that how people perceive social support is a significant factor for the RTW process that has not been given sufficient attention. ${ }^{35}$ In the present study, the case-management ecological model provides a theoretical basis for analyzing what domains and specific problems people with multimorbidity experience as the main barriers, and how they experience the importance of RECOs' measures and support with regard to these domains.

\section{The Present Study}

In this study we interviewed people on SA with multimorbidity who have had contact with a RECO. The first aim was to explore what problems and barriers people with multimorbidity experience during their rehabilitation and RTW process. The second aim was to explore in which domains the support of RECO is perceived to be of importance. The analysis is guided by the evidencebased and validated case-management ecological model previously described.

\section{Method}

In this study, data were collected through individual semistructured interviews, a method appropriate for generating knowledge to inform social or healthcare interventions. ${ }^{36}$ Because the COVID-19 pandemic prohibited in-person interviews during the data collection period, we used telephone interviews as a means of data collection.

\section{Participants and Recruitment}

The participants were people with multimorbidity who had several contacts with a RECO while on SA during the winter of 2019 and spring of 2020 in Stockholm County, Sweden. Thirteen RECOs working at primary healthcare, psychiatry or addiction centers were asked by the project leader (VS) to send a letter about the study to three to six such patients each (in total 70 patients). The invitation was sent once, with no reminder. The letter included information about the study and that participation was voluntary, the project leader's contact information for further questions or to notify interest in participating, a consent form and a pre-paid response envelope. Thirteen persons replied with a signed consent form together with contact information. These were contacted by the interviewer (AA), who informed them verbally about the study and scheduled a time for an interview. One person who sent in a content form declined to participate when contacted by the interviewer. The reason for declining was not having enough knowledge about RECO. The researchers had no information about those who were invited, and the RECOs have no information about the final participants.

The 12 participants were informed that research participation was independent of their rehabilitation and SA, and that their participation and data would be treated strictly confidentially and not passed on, for example to RECOs, other healthcare staff, employers, SIA or other authorities. The participants' written consent included publication of anonymized responses. All procedures performed in the present study were in accordance with the ethical standards of the Swedish Ethical Review Authority and with the 1964 Declaration of Helsinki and its later 
amendments and comparable ethical standards. The present study was approved by the Swedish Ethical Review Authority (Dnr 2020-00403).

\section{Interviews}

A semi-structured interview guide was developed, based on previous literature covering RTW coordination. The interview guide addressed three central topics: (1) the patients' SA and factors hindering their capacity for rehabilitation and RTW, (2) their views of the rehabilitation process, and (3) their experience of the support they received from the RECO. We also asked them about how they experienced being interviewed via telephone, findings which are published elsewhere. Each interview began by asking the participant to describe themselves with regard to for example occupation and working life. The interviews were conducted in a responsive manner, allowing the participants to speak freely about their experiences. All 12 interviews were conducted from May through August 2020 and lasted 30-74 minutes each. The interviews were conducted in Swedish via telephone, were recorded and transcribed verbatim. Participants' names, personal information and places were omitted from the transcriptions.

\section{Coding and Analysis Process}

Thematic analysis was used as it is not bound by a preexisting theoretical framework and is flexible with regard to the choice of theory that we as researchers want to use in the search for patterns and themes. ${ }^{37}$ The analysis was conducted by VS and AA. Initially, both authors read all 12 interviews to get an overall impression of possible themes in the data. After that, meaning bearing units were identified and sorted based on the manifest content, and finally condensed. Thereafter, a dialogue took place about how to theoretically understand the participants' experiences, leading to a theoretical model for RTW that could reflect the different dimensions and guide the further analyses. The third step thus took an abductive approach. $^{37,38}$ Six transcripts were chosen in order to identify preliminary themes relating to the four domains in the case-management ecological model, by abstracting and coding the condensed units corresponding with the two aims into different themes. AA made a first draft of the themes, after which VS read through the six interviews. There was then a joint discussion about naming themes and assigning units to respective themes. This analytical step was repeated for the remaining interviews.
In the final step, different views within the units were identified, emphasizing the differing experiences among the participants. ${ }^{39} \mathrm{VS}$ and AA continuously discussed the coding during the analysis process until consensus was reached and inter-coder reliability was established. ${ }^{40}$ The analysis process also involved some revisions of the casemanagement ecological model, which are described in the final discussion. Finally, the analysis was discussed with $\mathrm{EF}$, and some clarifying revisions were made.

\section{Results}

The 12 participants, nine females and three males, were all living in Stockholm County, Sweden. They were or had been on SA for periods of 6 months up to approximately four years, and most were working part-time at the time of the interview (Table 1). All had at least two diagnoses and a majority described psychosocial problems affecting their symptoms, rehabilitation or RTW (Table 2). Most were still in contact with a RECO at the time of the interview.

The findings are presented in two parts, one for each of the two aim. For each aim, analysis was made on the basis of the four domains in the case management ecological model. During the analysis, the model was revised and adopted to the Swedish context, leading to adjustment in the domain names from the original model. This means that some texts in Figure 1 differ from those in the original figure created by Costa-Black et al. ${ }^{35}$ The revisions are further elaborated in the final discussion.

\section{Problem Descriptions}

Problems and barriers were prevalent in all four domains, with several categories within each domain (Figure 1).

\section{The Personal System}

Three categories were found in the personal system: State of health, Difficulties in social relationships and lack of social support, and Socioeconomic difficulties.

\section{State of Health}

When describing their state of health the interviewees talked about somatic, psychological, neuropsychiatric and addictive symptoms and disorders - in varying combinations (see Table 1).

Difficulties in Social Relationships and Lack of Social Support

Although not common, some interviewees mentioned sexual abuse or other difficult circumstances during childhood. 
Table I Sociodemographic Characteristics of the Participant ( $=12$ )

\begin{tabular}{|c|c|}
\hline Characteristics & $n=12$ \\
\hline \multicolumn{2}{|l|}{ Gender } \\
\hline Female & 9 \\
\hline Male & 3 \\
\hline \multicolumn{2}{|l|}{ Age } \\
\hline Median years (range) & $48(34-50)$ \\
\hline \multicolumn{2}{|l|}{ Sickness absence } \\
\hline Full-time & 3 \\
\hline Part-time $(25,50$ or $75 \%)$ & 8 \\
\hline Returned to work & I \\
\hline \multicolumn{2}{|l|}{ Duration of sickness absence } \\
\hline Median years (range) & $1.5(0.5-4)$ \\
\hline \multicolumn{2}{|l|}{ Occupation } \\
\hline Office work & 9 \\
\hline Manual labor & 2 \\
\hline Unemployed & I \\
\hline \multicolumn{2}{|l|}{ Married or in a relationship } \\
\hline Yes & 6 \\
\hline No & 6 \\
\hline \multicolumn{2}{|l|}{ Children } \\
\hline Yes & 8 \\
\hline No & 4 \\
\hline \multicolumn{2}{|l|}{ Contact with RECO through } \\
\hline Primary care center & 7 \\
\hline Psychiatric or addiction clinic & 5 \\
\hline \multicolumn{2}{|l|}{ Number of contacts with RECO } \\
\hline More than 6 & 8 \\
\hline Up to 6 & 4 \\
\hline
\end{tabular}

This, in combination with not having support from friends, family or professionals, either as children or adults, had led to mistrust against professionals and support systems, involving failure to ask for or accept support that was offered.

Lack of social and emotional support from family, relatives and close friends, sometimes led to feeling lonely. Lack of support with informal caregiving was especially expressed by the female participants, who described unequal parenting where they were the main caregiver for children with special needs due to illness or disabilities. One interviewee stated that she in practice was the lone caregiver for her child as her husband was periodically also on SA. Another woman described a stressful life in which her husband was simply a "helping hand" rather than an equal responsible parent caring for their child with
Table 2 The Participants Self-Reported Diagnoses, Symptoms and Psychosocial Difficulties

\begin{tabular}{|c|c|}
\hline Participant & $\begin{array}{l}\text { Self-Reported Diagnoses, Symptoms and } \\
\text { Psychosocial Difficulties }\end{array}$ \\
\hline I & $\begin{array}{l}\text { Fatigue symptoms, depression, anxiety, partner with } \\
\text { depression }\end{array}$ \\
\hline 2 & $\begin{array}{l}\text { Fatigue symptoms, chronic headache, child with } \\
\text { ADHD and other problems }\end{array}$ \\
\hline 3 & $\begin{array}{l}\text { ADHD, depressive periods, tinnitus, drug addiction, } \\
\text { maltreated as child }\end{array}$ \\
\hline 4 & $\begin{array}{l}\text { Sleeping disorder, pain problems, depression, } \\
\text { childhood cancer survivor }\end{array}$ \\
\hline 5 & Heart problem, anxiety, fatigue symptoms \\
\hline 6 & $\begin{array}{l}\text { Bowel disease, depression, pain problems, sleeping } \\
\text { disorder, breast cancer survivor, alcohol addiction }\end{array}$ \\
\hline 7 & $\begin{array}{l}\text { Fatigue symptoms, depression, autism spectrum } \\
\text { disorder, PTSD, pain problems, maltreated as child }\end{array}$ \\
\hline 8 & Fatigue symptoms, sleep disorder, pain problems \\
\hline 9 & $\begin{array}{l}\text { Transient ischemic attack, severe headache, brain } \\
\text { fatigue, prostate cancer, stomach problems, Covid- } 19\end{array}$ \\
\hline 10 & $\begin{array}{l}\text { Sleeping disorder, fatigue symptoms, children with } \\
\text { chronic somatic disease and mental health problems }\end{array}$ \\
\hline II & $\begin{array}{l}\text { Chronic fatigue syndrome, pain problems, } \\
\text { rheumatoid arthritis }\end{array}$ \\
\hline 12 & $\begin{array}{l}\text { Fatigue symptoms, ADD, child with mental health } \\
\text { problems }\end{array}$ \\
\hline
\end{tabular}

neuropsychiatric disorders who required extra care. A third woman described lack of support for caring for a child with a chronic disease, who required care both day and night, thereby affecting her sleep.

So, what's difficult is that my sleep problems are mainly external factors, and you can't work with them that way. If it's only internal stress that makes you sleep poorly, it's one thing, then you can work with different things to change it. But I can't change my daughter's diagnosis, so to speak. (Participant 10)

These female participants described the burden of informal caregiving as a barrier to their own rehabilitation, as it meant living with, for example, constantly interrupted sleep, leading to fatigue symptoms. Another woman said "it was very good to be able to be honest and tell as it is, that it's not just the job, or it's almost not the job at all but rather what's going on at home" 


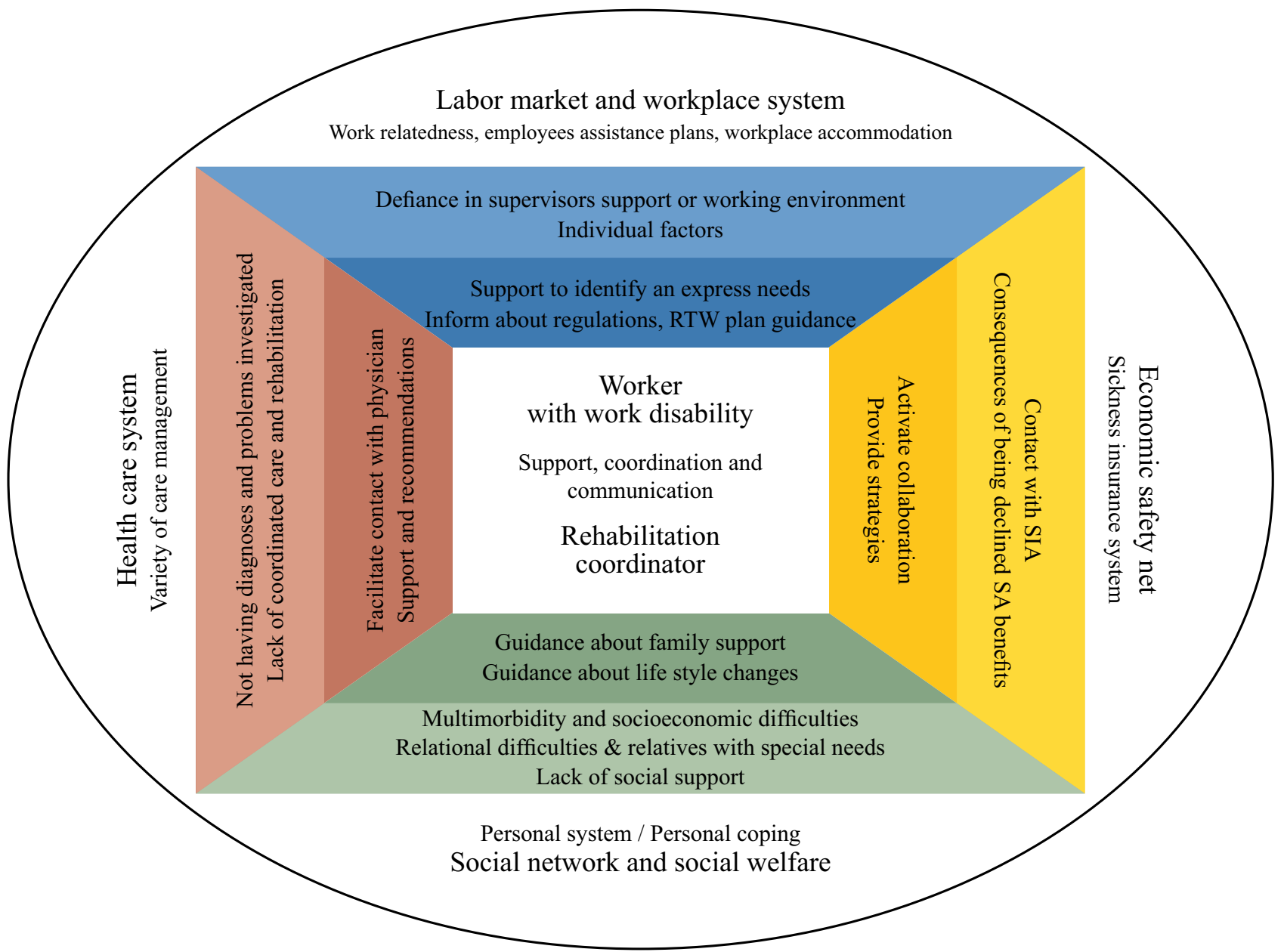

Figure I Experienced problems for participants' rehabilitation and RTW, and what type of RECO interventions the participants find supportive - in relation to the four dimensions in the case-management ecological model. The adapted model originates from the model created by Costa-Black, Feuerstein and Loisel. ${ }^{35}$

(Participant 2) when describing how it was the difficulties in caring for her multimorbid children that had made her more and more unable to cope with stress at work.

Other participants described deaths in the family, children moving out, divorces or other crises in partner relationships as having a negative effect on their self-confidence and mental health, thus affecting their RTW negatively.

\section{Socioeconomic Difficulties}

Socioeconomic difficulties were described as barriers to rehabilitation, for example overcrowded living or not being able to afford public transport, making it harder to stay in contact with friends and family. Some described a constant worry about loss of income or being refused SA benefits. One participant described her lack of education as a barrier to finding work.

\section{The Healthcare System}

The two categories in the healthcare domain concerned the need for a holistic investigation of diseases and problems, and the holistic coordination of healthcare providers and rehabilitation.

\section{Holistic Investigation of Diseases and Problems}

Although some participants had had their symptoms sufficiently investigated, several described receiving the wrong diagnosis on their first healthcare visits, or not having their symptoms fully investigated. This was sometimes described as the notion that pain symptoms were psychologized, that they had atypical symptoms difficult to classify, or that it was difficult to define their main problems because the symptoms tended to intensify each other. One woman described how difficult it was to decide which of her symptoms were most important for her work disability: 
It's the fatigue more than anything. But I also have back pain problems, and periodically I can't work because of that. But that's not ... I don't think that was even mentioned in the sick leave procedure, if that's what you call it. I haven't brought it up with anyone in healthcare, really, because they can't do anything about it. And then there are depression problems, or whatever you want to call them. It's a pretty ... I've had depressive symptoms for ... pretty constantly for maybe six, seven years, but not so severe that it's like super serious. But they never completely disappear either. (Participant 4)

Others described symptoms being excluded from the sickness certificate, or a lack of work ability assessment. Some felt that none of their diseases were, on their own, severe enough for SA, but that the sum of their symptoms had a significant impact on their health and work ability. They stressed the importance of having the cause of their symptoms investigated, to obtain an accurate diagnosis, and thus the right treatment and rehabilitation.

\section{Holistic Rehabilitation and Coordinated Healthcare Providers}

The multimorbidity was described as making it difficult or even impossible to take part in common treatment and rehabilitation programs, as these most often were designed for individuals with single diseases. The lack of rehabilitation programs that were modified to their combined diseases and needs sometimes led to worse symptoms. For example, one participant with fatigue syndrome, autism spectrum disorder, PTSD, and pain problems described how she had to choose between a group rehabilitation program for pain or one for fatigue syndrome, although she needed both. She also described how the rehabilitation program did not take into consideration the magnitude and complexity of her current state of health which was a consequence of her autism:

It was a bit general, like "Do what feels good. And you have to learn to get a balance. And you have to learn not to do too much, even if you feel you have the energy". That is, it's left to me to judge, and I'm a person who can't judge ... It's very difficult for me to judge levels of emotions, pain, whether I have the energy or not. And I don't know if it has to do with my autism, but I kind of don't understand ... Other people say things like "Yes, but today I'm home because I'm sick", and I don't understand where the boundary is for staying home. I understand that if I can't even get out of bed, then I have to stay home, because I can't get up. Or if I have a fever. But everything beyond that, I get like "OK, I guess I'll try to get up. Well, that went well. I'll try to eat. Yes, that went well". And then I go all the way, and finally end up at work. And people can say "Oh my god, you don't look well at all. Shouldn't you go home?" "Okay, yes, I guess I'll do that then." And then I go home. So in that way, rehabilitation is tough when you have to take so much responsibility yourself. (Participant 7)

Some also had the experience of being transferred between different healthcare providers, as a consequence of having several diseases. The lack of a holistic approach made some feel that they were abandoned, seen as a problem no one wanted to handle, and that the healthcare system excluded them.

Several participants described having difficulty making themselves understood to others, or understanding their own needs or possible options. Having numerous physicians and other healthcare contacts made it difficult to uphold an integrated communication with all. This involved different rehabilitation plans, not knowing who to contact, and sometimes this consumed so much time and energy that the rehabilitation efforts were perceived as hindering recovery and leading to worse health and prolonged SA.

Several participants described their problems with getting an appointment with a physician, or repeatedly encountering new physicians. Some also talked about inexperienced physicians with poor knowledge about their diseases, leading to poorly written SA certificates, or insufficient treatment and rehabilitation.

\section{The Labor Market and the Workplace System}

Three categories were identified in this domain: Work environment problems, Deficiencies in employer support, and Difficulties in relation to the Public Employment Services.

\section{Work Environment Problems}

Work environment factors were described as affecting RTW. These included stress, high workload, staff shortages, or colleagues or a manager who also were on SA. Participants said that they needed support in finding ways to make adjustment to work demands and to accept a new, slower work pace. Difficulty in dealing with work environment problems led to feelings of being a burden to colleagues, managers and clients. 


\section{Deficiencies in Employer Support}

Some participants spoke about employers who did not have time to make an appropriate RTW plan or who rejected occupational healthcare even though it was available. Other difficulties were lack of support in making work adjustments, which caused one participant to reduce her working hours. Many stressed the importance of having an employer who understood one's situation by accommodating alternative work tasks. A participant who struggled with alcohol and drug addiction described how his employer threatened to fire him if his addiction continued.

Difficulties in Relation to the Public Employment Services One participant without a job to return to talked about the difficulty of knowing her rights vis à vis the Public Employment Services. She was worried about not being assigned a workplace for her work training program that was appropriate for her problems and work disabilities. She also felt that the officer mistrusted her motivation for getting a new job.

\section{The Sickness Insurance System}

The domain of sickness insurance system includes two categories: Difficulties in contacts with the SIA and Consequences of being (or being worried about being) refused SA benefits.

\section{Difficulties in Contact with the Social Insurance Agency} Interviewees spoke about the problem of getting in touch with their SIA officer. Those who succeeded sometimes found it difficult to verbalize their symptoms, difficulties or needs.

\section{Consequences of Being (or Being Worried About Being) Refused SA Benefits}

Several participants worried about being refused SA benefits and about the long waiting times for decisions. One argued that SIA "makes people more sick" (Participant 9). Those who had a diagnosis that was perceived to be caused by their social difficulties felt anxious because they anticipated problems regarding their application for SA benefits. This is because the criteria for SA in relation to social problems are sometimes perceived to be unclear. SA should be granted when work incapacity is caused by a medical diagnosis, which may be caused by social circumstances. At the same time, SA can be refused if work incapacity is caused by social circumstances while there is no clear medical diagnosis. Participants who had been refused SA benefits described financial concerns, being forced to RTW, and sickness presenteeism.

\section{RECO Interventions of Importance for RTW}

Regarding our second aim, support from RECOs was found to be important in all four domains in the model (Figure 1). The participants gave examples of the support they had received, or had not received, and why and how such support enabled their RTW process. The analysis showed that the RECO, depending on the participant's particular situation and needs, are perceived as important for coordinating contacts between the different domains. Since many spoke about the importance of coordination irrespective of actor and domain, we present this as a first category before the four separate domains.

\section{The Importance of a Multi-Level Coordinator}

The participants experienced RECO as important for coordinating the various actors they had contact with, and one said:

I just think that a rehabilitation coordinator ... One should be offered to everyone who has several diseases or is on a long sickness absence, or ... Because there are times when you feel that you can't cope, that you're on your knees. And it's the social insurance agency, and it's your doctor GP, and what should you say and what should you do? What is the most sensible thing to do? Should I? Shouldn't I? So it's great to be able to discuss it with someone who knows about it and has loads of experience. Absolutely fantastic. And by now she's probably the one who knows absolutely most about me. (Participant 5)

This participant argues that particularly persons with multimorbidity or on long SA may need the support of a RECO because of the many different contacts which can be demanding to manage. Those who did not receive help coordinating contacts with actors in the different domains stressed the importance of such support and how lack of it made their rehabilitation and RTW process more difficult. One said:

And she [RECO] still hasn't called. I guess it's been problematic./ ... /And it's also a bit like, it hasn't felt as if there has been any cohesive commitment, but that it's, like, sporadic. That I should contact her if there's a problem. I thought it would be more of a process she'd be involved in and keep track of throughout the journey, until I kind of end up somewhere. But that doesn't seem to 
be the case. There seems to be a lot that's up to me to arrange, and that's difficult for me, unfortunately. (Participant 7)

Participants with diseases that reduced their ability to initiate or arrange their own rehabilitation process were those who most strongly expressed the need for more sturdy coordination and their RECO calling them for follow-ups.

\section{The Personal System}

While some participants appreciated RECO's advice, for example about diet and exercise in order to improve their health, others had become more ill after following the RECO's physiotherapeutic advice about exercise.

Other forms of support in the personal system included providing information or coordinating contacts with other healthcare services or authorities in order to address psychosocial factors hindering rehabilitation. When asked if she had received any help from the RECO regarding difficulties in her family situation, one woman answered:

No, well, she ... I'm talking to her about it, and she was the one who suggested some family counseling, or some kind of therapist, and so on. So we discussed it a bit, and then she said that you could call the municipality and talk to them, because the municipality usually has family counseling where you can go X number of times, and so on. So, she was the one who suggested it, that's why I contacted the family counseling service. But otherwise I don't think she would have been able to do much there, I think. But she functions like a ... she functioned like a psychologist in the end after all, because we talked about everything. So that was very good. (Participant 1)

Other participants described wanting more support with the social difficulties that caused ill-health and SA, and that the RECO did not offer such support.

\section{The Healthcare System}

RECOs were described as initiating and promoting coordination within the healthcare system (for example with physicians, psychologists, health social workers). They also communicated with physicians about the participant's health condition and recommended or helped participants to get in touch with a physician. One said that the RECO had "been able to book a meeting directly with the physician and that I've been able to get an appointment." (Participant 11). RECOs also provided options for treatment and coordinated different treatments. Sometimes, the
RECO advised them to limit the number of healthcare contacts in order to have more cohesive treatment.

For many participants, the RECO acted as a psychotherapist or counselor with whom they could talk about anything. This was described as comforting and as valuable to their recovery and RTW process. One said that the RTW process would have "been much more difficult otherwise. I'm not sure if I would've been able to return to work full-time if it wasn't for her" (Participant 9). Several said that the RECO increased their sense of security in their situation, with the RECO being described as the person in the healthcare system they had most frequent contact with.

\section{The Labor Market and Workplace System}

In relation to the workplace, RECOs were described as helping participants to articulate their needs and inability to work full-time, which facilitated their communication with the employer. One said:

Yes, it's that I was helped to talk to my manager in a good way. In a calm and composed way, I'd say. I was nervous on the way there, but I was very calm when I left. (Participant 6)

Sometimes the RECO communicated such issues directly to the employer, with the participant's approval. RECO could thus function as a support in the participant's preparations for meetings, as well as physically attend such meetings. RECOs also gave feedback about the RTW plan and told participants about their rights and obligations vis à vis their employer. This type of support was deemed important for the RTW process. In some cases, insufficient support from a RECO had led to participants cutting their employment from full to part-time, which affected their sickness benefit qualifying income. One interviewee who did not have an employment describes different actors having different opinions about her situation, when it was suggested that she should start at a new workplace run by Samhall, a state-owned company providing work for people with disabilities but who are able to work:

The rehabilitation coordinator has an opinion, which is "It doesn't sound at all like it would be good for you to end up in that [work]place". And Samhall says "It's the only place we can offer you". And the Public Employment Service says "There's no reason for you to not go there, because you aren't on full-time sick leave". And yes, then I end up in a ... unfortunately in a situation where I feel 
"Well, I just have to find my way through this". (Participant 7)

This participant said she felt lonely and that she needed more active support from the RECO in communicating with the involved actors, as well as more psychosocial support and more responsive encounters.

\section{The Sickness Insurance System}

The participants appreciated the support they received with their contacts with the SIA. RECOs helped participants to express themselves in meetings with the SIA regarding their entitlement to SA benefits, or they talked directly with the SIA. RECOs also told participants about possible economic benefits from the SIA. Some RECOs suggested useful strategies, for example not to reveal social difficulties in their personal lives, and one woman said:

I also think she has a good insight into the Swedish Social Insurance Agency, she's told me 'you absolutely mustn't mention anything about how hard it is at home, because then there won't be any money' [laughs]. (Participant 2)

This referred to the possibility that the SIA might deny SA benefits if they perceive that a persons' work incapacity is due to social difficulties rather than a medical diagnosis, which is the criterion for being granted SA benefits.

\section{Discussion}

The two aims of the present study were 1) to explore what problems and barriers people on SA with multimorbidity experience during their rehabilitation and RTW process, and 2) to explore in which domains the support of RECO is perceived to be of importance. Using the casemanagement ecological model as a basis, the analysis showed that problems and barriers as well as support, or lack of support, were found in all four domains of the model, indicating complex life situations and multiple factors hindering RTW, presented on multiple levels (micro, meso, exo, macro). This indicates the importance of focusing on the person's whole life situation, not just their health status, when facilitating RTW for people with multimorbidity and psychosocial difficulties, thereby using a salutogenic approach in line with the work description of RECOs. ${ }^{28}$ The results will be further discussed and related to this work description.

The health and social state of the participants varied greatly, with different combinations of diseases and complicating psychosocial difficulties affecting their RTW.
The complexity of the participants' problems meant that these were not always sufficiently identified or diagnosed. It also meant that participation in rehabilitation programs designed for single diseases, that were not modified to accommodate their combined diseases, complexities and needs, sometimes led to worse symptoms. As a consequence, the participants expressed the need for a holistic rehabilitation and coordinated healthcare providers. Other scholars have also suggested that interventions should have a cross-disease approach ${ }^{11,41}$ and should target disease-generic factors rather than disease-specific factors. ${ }^{42}$ Other important findings with regard to factors which hinder RTW for people with multimorbidity and psychosocial difficulties were the extra burden of having numerous healthcare contacts, and socioeconomic and psychosocial difficulties such as overcrowded living and lack of money or emotional or social support. These are all risk factors for ill-health, ${ }^{43}$ and here defined by some participants as causing their symptoms and diseases, and hindering their RTW process. What characterizes people with multimorbidity (especially those with social difficulties) is living with the extra burden of stress factors which they are not always able to deal with. ${ }^{6}$

The main finding with regard to the second aim of the study was that RECO was described as being important in all domains. This is in line with the RECOs work description as coordinating contacts in all these domains. ${ }^{28}$ The most evident example of perceived good support was found in the healthcare domain, where the RECO for example could advise about and ease communication with the numerous healthcare contacts. This confirms previous research into RECO, ${ }^{32}$ and is not surprising because they are employed in healthcare settings. In line with previous studies, ${ }^{29,30,32}$ the RECO was regarded as important for facilitating communication and coordinating various stakeholders, both inside and outside of healthcare. However, the RECO was perceived as providing less advice and coordination with regard to "the labor market and the workplace system" and "the sickness insurance system", and very little advice in "the personal system". It was evident, however, that the participants appreciated RECOs not only for coordinating their contacts with stakeholders, but also for their support with expressing their symptoms, problems and needs in their contacts with, for example, physicians, employers, SIA officers or the Public Employment Services. While previous studies have stressed that RECOs are important for information sharing, mediating and upholding clear communication at meetings 
with stakeholders, ${ }^{30,32}$ our findings add that RECO can be important for the person on SA in the preparation before such contacts. This preparatory function should be taken into consideration in the further development of the RECO's role. Participants also regarded the RECO attending meetings with stakeholders as offloading and supportive. The consequences for the participants were sometimes negative if the RECO did not attend, or had a passive approach at such meetings. As such meetings are often decided at short notice, the RECOs were not always able to join. This highlighted the need among RECOs to retain flexibility in their work-calendar, to be able to support people on SA at meetings.

Another main finding was that difficulties in social relationships and lack of social support in combination with multimorbidity hindered participants' RTW process. Women described the extra burden of informal caring, especially those who had children with special needs. This confirms previous research. ${ }^{14,16,17}$ They also reported a lack of support with their children, both from RECOs and their partners, which also confirms previous findings. ${ }^{44}$ Although the RECO is supposed to promote gender equal rehabilitation and $\mathrm{RTW}^{28}$ the present findings suggest that more can be done to mitigate genderspecific factors which hinder RTW. The RECO are not responsible for solving gender inequality issues, or lack of social support in general, but the findings pose questions about how such barriers can be targeted to promote women's RTW. For people with multimorbidity, and women in particular, social support related to the personal system seems to be an important aspect of the RTW process.

Although the participants did not receive support with the psychosocial difficulties which hindered their RTW, the RECO was described as someone they talked to about such difficulties. The RECO thus acted as a therapist, rather than coordinating or informing about available solutions and social support that could facilitate rehabilitation and contribute to RTW. Participants who lacked contact with, for example, a psychologist, counselor or a health social worker, appreciated that the RECO could fulfill the role of therapist for them. We do not know what training or educational background the particular RECOs had, but they are seldom trained in psychotherapy, other than a basic course in, for example, motivational interviewing. This suggests that RECOs should be more active in referring patients to other professionals. One could also consider whether RECOs should be more active in directing people whose main problem is loneliness to patient organizations or other non-government organizations where they might be able to develop long-lasting and supportive social relationships.

Although the case-management ecological model was originally developed for RTW for workers with disability from musculoskeletal pain, ${ }^{35}$ we found it applicable to people with multimorbidity and psychosocial problems. The model was useful to analyze in which domains the described problems and RECO interventions took place. However, we revised and adapted the model to the Swedish welfare state context in three ways, making it more suitable for our analysis (Figure 1).

Firstly, in order to include people without a current job, the domain "Workplace system" was revised to "Labor market and workplace system". Secondly, in an extensive welfare state such as Sweden, the concepts of legislation and insurance are relevant for all the domains and cannot solely be used to describe the insurance system, as in Costa-Black, Feuerstein and Loisel's model. ${ }^{35}$ We therefore revised the name of the domain "Legislative and insurance system" to "Sickness insurance system" to make this domain clearer in relation to the other domains. Thirdly, the authors of the model associate the "Legislative and insurance system" with "Society's safety net", which can be problematized. From the Swedish point of view, society's safety net includes, for example, labor laws, aspects of healthcare, as well as the various individual and family services provided by the social welfare system. We therefore changed "Society's safety net" to "Economic safety net" in order to relate to the "Sickness insurance system", and added "Social network and social welfare" (including, for example, family counseling or non-financial public support to reduce the burden of informal caregiving) to the domain "Personal system/ personal coping". By doing this, the revised model also includes socioeconomic and non-financial social factors of relevance for people with multimorbidity and the social difficulties that sometimes hinder their RTW.

\section{Strengths and Limitations}

While previous studies of RTW interventions often focus on particular diseases, a strength of the present study is the focus on people with multimorbidity and complicating psychosocial difficulties. This study adds knowledge about the barriers this group experience in their rehabilitation and RTW process, and how social difficulties impact on their RTW. In particular, this study contributes to the 
large gap in the literature regarding research into RTW interventions for people with multimorbidity, by adding new knowledge about their self-reported needs in relation to RTW interventions and their experience of RECO interventions.

However, the study also has some limitations. One is that the sample is restricted to one city region. Another is that we do not have the views of RECOs or other stakeholders. The fact that it was the RECOs who selected the patients who were invited to participate in the study, might, for example, have led to individuals with language barriers or who had ended the contact early because of disappointment were not invited. Those who participated probably differ in some aspects from those who did not, but we do not know how.

\section{Conclusion}

People with multimorbidity and psychosocial difficulties experience problems and perceive rehabilitation coordinator interventions as important in all the domains investigated. The RECOs gave most advice and coordination in relation to healthcare and employers, and less when it came to contacts with the SIA and their psychosocial difficulties in the personal system, which seem to be more common among women. Lack of advice and lack of coordination or rehabilitation programs that were modified to their combined diseases and complexities were associated with lengthier SA, presenteeism, worse health or employment conditions, or the social risk factors for SA not being recognized.

\section{Acknowledgments}

The authors wish to thank the participants for sharing their stories with us.

\section{Funding}

This research was financially supported by grants from The Kamprad Family Foundation for Research (Reference No 20190271). The funding body had no role in the design, execution, interpretation, or writing of the study.

\section{Disclosure}

Dr Veronica Svärd reports grants from The Kamprad Family Foundation for Research (Reference No 20190271), during the conduct of the study. The authors of this manuscript have no conflicts of interest to declare.

\section{References}

1. Xu X, Mishra GD, Jones M. Evidence on multimorbidity from definition to intervention: an overview of systematic reviews. Ageing Res Rev. 2017;37:53-68. doi:10.1016/j.arr.2017.05.003

2. Garrelfs SF, Donker-Cools BH, Wind H, Frings-Dresen MH. Returnto-work in patients with acquired brain injury and psychiatric disorders as a comorbidity: a systematic review. Brain Inj. 2015;29 (5):550-557. doi:10.3109/02699052.2014.995227

3. Le Reste JY, Nabbe P, Manceau B, et al. The European general practice research network presents a comprehensive definition of multimorbidity in family medicine and long term care, following a systematic review of relevant literature. J Am Med Dir Assoc. 2013;14(5):319-325. doi:10.1016/j.jamda.2013.01.001

4. Glynn LG, Valderas JM, Healy P, et al. The prevalence of multimorbidity in primary care and its effect on health care utilization and cost. Fam Pract. 2011;28(5):516-523. doi:10.1093/fampra/cmr013

5. Peart A, Barton C, Lewis V, Russell G. A state-of-the-art review of the experience of care coordination interventions for people living with multimorbidity. J Clin Nurs. 2020;29(9-10):1445-1456. doi:10.1111/jocn.15206

6. Zullig LL, Whitson HE, Hastings SN, et al. A systematic review of conceptual frameworks of medical complexity and new model development. J Gen Intern Med. 2016;31(3):329-337. doi:10.1007/ s11606-015-3512-2

7. Korkeila M, Alexanderson K, Norlund A. Finns det samband mellan samsjuklighet och sjukfrånvaro? En systematisk litteraturöversikt [Is there an association between comorbidity and sick leave? A systematic review] (In Swedish). The Swedish Ministry of Social Affairs; 2010. Available from: https://www.regeringen.se/rattsligadokument/statens-offentliga-utredningar/2010/12/sou-201089/.

Accessed March 6, 2021.

8. Linder J, Ekholm KS, Jansen GB, Lundh G, Ekholm J. Long-term sick leavers with difficulty in resuming work: comparisons between psychiatric-somatic comorbidity and monodiagnosis. Int $J$ Rehabil Res. 2009;32(1):20-35. doi:10.1097/MRR.0b013e328306351d

9. Turi E, Conley Y, Stanfill AG. A literature review of psychosocial comorbidities related to working capacity following aneurysmal subarachnoid hemorrhage. $J$ Neurosci Nurs. 2017;49(3):179. doi:10.1097/JNN.0000000000000281

10. Zieger M, Luppa M, Meisel HJ, et al. The impact of psychiatric comorbidity on the return to work in patients undergoing herniated disc surgery. J Occup Rehabil. 2011;21(1):54-65. doi:10.1007/ s10926-010-9257-1

11. Gragnano A, Negrini A, Miglioretti M, Corbière M. Common psychosocial factors predicting return to work after common mental disorders, cardiovascular diseases, and cancers: a review of reviews supporting a cross-disease approach. J Occup Rehabil. 2018;28 (2):215-231. doi:10.1007/s10926-017-9714-1

12. Bültmann U, Siegrist J. Handbook of Disability, Work and Health. Cham: Springer Nature; 2020.

13. Lindqvist R. Vocational rehabilitation between work and welfare-the Swedish experience. Scand J Disabil Res. 2003;5(1):68-92. doi:10.1080/15017410309512612

14. Nilsen W, Skipstein A, Østby KA, Mykletun A. Examination of the double burden hypothesis - a systematic review of work-family conflict and sickness absence. Eur J Public Health. 2017;27(3):465-471. doi:10.1093/eurpub/ckx054

15. Gautun H, Hagen K. How do middle-aged employees combine work with caring for elderly parents? Community Work Fam. 2010;13 (4):393-409. doi:10.1080/13668800903360625

16. Hjelmstedt S, Lindahl Norberg A, Montgomery S, Hed Myrberg I, Hovén E. Sick leave among parents of children with cancer-a national cohort study. Acta Oncol. 2017;56(5):692-697. doi:10.1080/0284186X.2016.1275780 
17. Brekke I, Nadim M. Gendered effects of intensified care burdens: employment and sickness absence in families with chronically sick or disabled children in Norway. Work Employ Soc. 2017;31(3):391-408. doi:10.1177/0950017015625616

18. The Swedish Social Insurance Inspectorate. Social problematik och sjukskrivning [Social difficulties and sick leave] (In Swedish). Stockholm; 2018. Available from: https://inspsf.se/publikationer/rap porter/2018/2018-05-03-social-problematik-ochsjukskrivning-handlaggning. Accessed March 6, 2021.

19. Higgins A, O’Halloran P, Porter S. Management of long term sickness absence: a systematic realist review. J Occup Rehabil. 2012;22 (3):322-332. doi:10.1007/s10926-012-9362-4

20. Nieuwenhuijsen K, Verbeek JH, Neumeyer-Gromen A, Verhoeven AC, Bültmann U, Faber B. Interventions to improve return to work in depressed people. Cochrane Database Syst Rev. 2020;10(10). doi:10.1002/14651858.CD006237.pub4

21. Nazarov S, Manuwald U, Leonardi M, et al. Chronic diseases and employment: which interventions support the maintenance of work and return to work among workers with chronic illnesses? A systematic review. Int J Environ Res Public Health. 2019;16 (10):1864. doi:10.3390/ijerph16101864

22. Skarpaas LS, Haveraaen LA, Småstuen MC, Shaw WS, Aas RW. Horizontal return to work coordination was more common in RTW programs than the recommended vertical coordination. The Rapid-RTW cohort study. BMC Health Serv Res. 2019;19(1):759. doi:10.1186/s12913-019-4607-y

23. Vogel N, Schandelmaier S, Zumbrunn T, et al. Return-to-work coordination programmes for improving return to work in workers on sick leave. Cochrane Database Syst Rev. 2017.

24. MacEachen E, McDonald E, Neiterman E, et al. Return to work for mental ill-health: a scoping review exploring the impact and role of return-to-work coordinators. J Occup Rehabil. 2020;1-11.

25. Wallstedt-Paulsson E, Erlandsson LK, Eklund M. Client experiences in work rehabilitation in Sweden: a One-Year Follow-Up Study. Occup Ther Int. 2007;14(1):28-41. doi:10.1002/oti.223

26. Williams-Whitt K, Bültmann U, Amick B, Munir F, Tveito TH, Anema JR. Workplace interventions to prevent disability from both the scientific and practice perspectives: a comparison of scientific literature, grey literature and stakeholder observations. J Occup Rehabil. 2016;26(4):417-433. doi:10.1007/s10926-016-9664-z

27. Cancelliere C, Donovan J, Stochkendahl MJ, et al. Factors affecting return to work after injury or illness: best evidence synthesis of systematic reviews. Chiropr Man Therap. 2016;24(1):32. doi:10.1186/s12998-016-0113-z

28. The Swedish Association of Local Authorities and Regions. Metodbok för koordinering. [Method book for coordination]. Available from: https://skr.se/tjanster/merfranskr/rapporterochskrif ter/publikationer/metodbokforkoordineringavsjukskrivningochrehabil iteringforhalsoochsjukvarden.31652.html. Accessed March 6, 2021.

29. Holmlund L, Hellman T, Engblom M, et al. Coordination of return-to-work for employees on sick leave due to common mental disorders: facilitators and barriers. Disabil Rehabil. 2020:1-9.
30. Strömbäck M, Fjellman-Wiklund A, Keisu S, Sturesson M, Eskilsson T. Restoring confidence in return to work: a qualitative study of the experiences of persons with exhaustion disorder after a dialogue-based workplace intervention. PLoS One. 2020;15(7): e0234897. doi:10.1371/journal.pone.0234897

31. Holmlund L, Guidetti S, Hultling C, Seiger Å, Eriksson G, Asaba E. Evaluating the feasibility of ReWork-SCI: a person-centred intervention for return-to-work after spinal cord injury. BMJ Open. 2020;10 (8):e036000. doi:10.1136/bmjopen-2019-036000

32. Skoglund I, Petersson E-L, Hange D. A bridge over troubled water? A qualitative study of primary care patients' experiences of a rehabilitation program. $J$ Multidiscip Healthc. 2018;11:457. doi:10.2147/JMDH.S166866

33. Bültmann U, Brouwer S. Individual-level psychosocial factors and work disability prevention. In: Handbook of Work Disability. Springer; 2013:149-162.

34. Ilmarinen J. Promoting Active Ageing in the Workplace. European agency for safety and health at work; 2012.

35. Costa-Black KM, Feuerstein M, Loisel P. Work disability models: past and present. In: Handbook of Work Disability. Springer; 2013:71-93.

36. Ogden T, Fixsen DL. Implementation Science: A Brief Overview and a Look Ahead. J Psychol. 2014;222(1):4-11.

37. Braun V, Clarke V. Using thematic analysis in psychology. Qual Res Psychol. 2006;3(2):77-101. doi:10.1191/1478088706qp063oa

38. Kennedy BL, Thornburg R. Deduction, induction, and abduction. In: The SAGE Handbook of Qualitative Data Collection. 2018:49-64.

39. Peled E, Leichtentritt R. The ethics of qualitative social work research. Qual Soc Work. 2002;1(2):145-169. doi:10.1177/ 147332500200100203

40. Castleberry A, Nolen A. Thematic analysis of qualitative research data: is it as easy as it sounds? Curr Pharm Teach Learn. 2018;10 (6):807-815. doi:10.1016/j.cptl.2018.03.019

41. Hara KW, Bjørngaard JH, Jacobsen HB, et al. Biopsychosocial predictors and trajectories of work participation after transdiagnostic occupational rehabilitation of participants with mental and somatic disorders: a Cohort Study. BMC Public Health. 2018;18(1):1014. doi:10.1186/s12889-018-5803-0

42. Sewdas R, De Wind A, Abma FI, Boot CR, Brouwer S. Personal and environmental factors influencing work participation among individuals with chronic diseases. In: Bültmann U, Siegrist J, editors. Handbook of Disability, Work and Health. Cham: Springer Nature; 2020:385-398.

43. Marmot M, Wilkinson R. Social Determinants of Health. 2nd ed. New York: Oxford University Press; 2006.

44. Nielsen MB, Madsen IE, Bultmann U, Christensen U, Diderichsen F, Rugulies R. Encounters between workers sick-listed with common mental disorders and return-to-work stakeholders. Does workers' gender matter? Scand J Public Health. 2013;41(2):191-197. doi:10.1177/1403494812470750
Journal of Multidisciplinary Healthcare

\section{Publish your work in this journal}

The Journal of Multidisciplinary Healthcare is an international, peerreviewed open-access journal that aims to represent and publish research in healthcare areas delivered by practitioners of different disciplines. This includes studies and reviews conducted by multidisciplinary teams as well as research which evaluates the results or conduct of such teams or healthcare processes in general. The journal

Submit your manuscript here: https://www. dovepress.com/journal-of-inflammation-research-journal covers a very wide range of areas and welcomes submissions from practitioners at all levels, from all over the world. The manuscript management system is completely online and includes a very quick and fair peer-review system. Visit http://www.dovepress.com/testimonials. php to read real quotes from published authors. 